\title{
Interaction between surface water and groundwater revealed by multi-tracer and statistical approaches in the Baiyangdian Lake watershed, North China Plain
}

\author{
Koichi Sakakibara ${ }^{1}$, Maki Tsujimura ${ }^{1}$, Xianfang Song ${ }^{2}$ and Jie Zhang ${ }^{1}$ \\ ${ }^{I}$ Graduate School of Life and Environmental Sciences, University of Tsukuba, Japan \\ ${ }^{2}$ Institute of Geographic Sciences and Natural Resources Research, Chinese Academy of Sciences, China
}

\begin{abstract}
:
The surface water/groundwater-continuum flow system is investigated through an intensive field survey downstream of the Baiyangdian Lake watershed, North China Plain. Oxygen and hydrogen isotope and chemical analyses are conducted on surface water, shallow groundwater, and deep groundwater and the results are processed by applying principal component and cluster analyses. The surface water of the Fu River, Tang Reservoir, and Baiyangdian Lake is strongly affected by anthropogenic influence, resulting in high nitrate-ion concentration, a distinct sodium-sulfate water-type derived from industrial wastewater, and enriched stable isotopic compositions due to accumulated evaporation, respectively. In some areas, shallow groundwater shows close chemical and isotopic affinity to surface water, indicating that surface water recharges to shallow groundwater. Deep groundwater shows lower chemical and isotopic signals than surface water and shallow groundwater. However, a slightly high nitrate-ion concentration is observed in some samples of deep groundwater, suggesting a partial communication between shallow and deep aquifers.
\end{abstract}

KEYWORDS North China Plain; groundwater recharge; stable isotopes; multi-classification analysis

\section{INTRODUCTION}

Understanding the interaction between surface water and groundwater is essential for water resource management, and multiple factors determine the hydrological continuum (Winter et al., 1998; Sophocleous, 2002). Traditionally, surface water and groundwater were considered different components of the hydrological cycle, although communication between the two water bodies was previously investigated in various scales (Winter et al., 1998; Barthel, 2014). More recently, intensive pumping from deep confined aquifers enabled communication between aquifers (Onodera et al., 2009; Yuan et al., 2013). Nevertheless, it is difficult to determine the timing and path of these interactions due to the significant spatial and temporal variability in the phenomenon (Keery et al., 2007), especially in low-precipitation regions (Scanlon et al., 2006; Jolly et al., 2008).

Hydrochemistry and environmental isotopic analysis were frequently applied to clarify surface water and groundwater interactions (Shivanna et al., 2004; Tsujimura et al.,
2007; Li et al., 2008; Qin et al., 2011; Yangui et al., 2011). Oxygen and hydrogen stable isotopes are ideal tracers to identify groundwater flow paths and recharge sources because of their conservative behavior (Nakaya et al., 2007; Liu and Yamanaka, 2012). The main inorganic water constituents characterize the water quality and are determined by the surrounding environment, including human activity, geology, and climate. Additionally, multivariate statistical techniques (e.g., principal component analysis and cluster analysis) have been effectively applied for data reduction and interpretation of the multi-constituent chemical components of water (Panda et al., 2006; Gmati et al., 2011).

The Baiyangdian Lake is the biggest freshwater lake in the North China Plain. However, since the 1980s, the water levels declined and the water quality deteriorated (Cui et al., 2010). Previous hydrological research in the Baiyangdian Lake watershed used multi-tracer analyses and numerical simulations (Wang et al., 2008; Liu et al., 2008; Shu et al., 2012; Yuan et al., 2013). The main cause of water shortage is overexploitation for agricultural and industrial purposes due to rapid economic development (Liu et al., 2006; Moiwo et al., 2010). Thus, groundwater-surface water interaction and inter-aquifer water communication possibly occur or are induced by excessive pumping. However, few studies link surface water and groundwater. Because the groundwater flow process in the Baiyangdian Lake watershed is very complicated due to the existence of multiple streams and reservoir networks, it is important to identify the surface water/groundwater-continuum flow system for the integrated water management and conservation of the water environment in the North China Plain.

Therefore, this study aims to clarify the interaction between surface water and groundwater in a multi-surface water and over-pumping area, the Baiyangdian Lake watershed, on the basis of the spatial distribution of the water bodies' geochemical characteristics. The research possibly provides new insight into future water management in multiple factors (multi-surface water, over-pumping, and low precipitation) regions.

\section{STUDY AREA}

The Baiyangdian Lake watershed (Figure 1) is located in the western part of the North China Plain. The mean annual surface air temperature is $12^{\circ} \mathrm{C}$, and the mean annual precip-

Received 4 February, 2016 Accepted 22 May, 2016

Published online 15 June, 2016

(C)2016, Japan Society of Hydrology and Water Resources. 


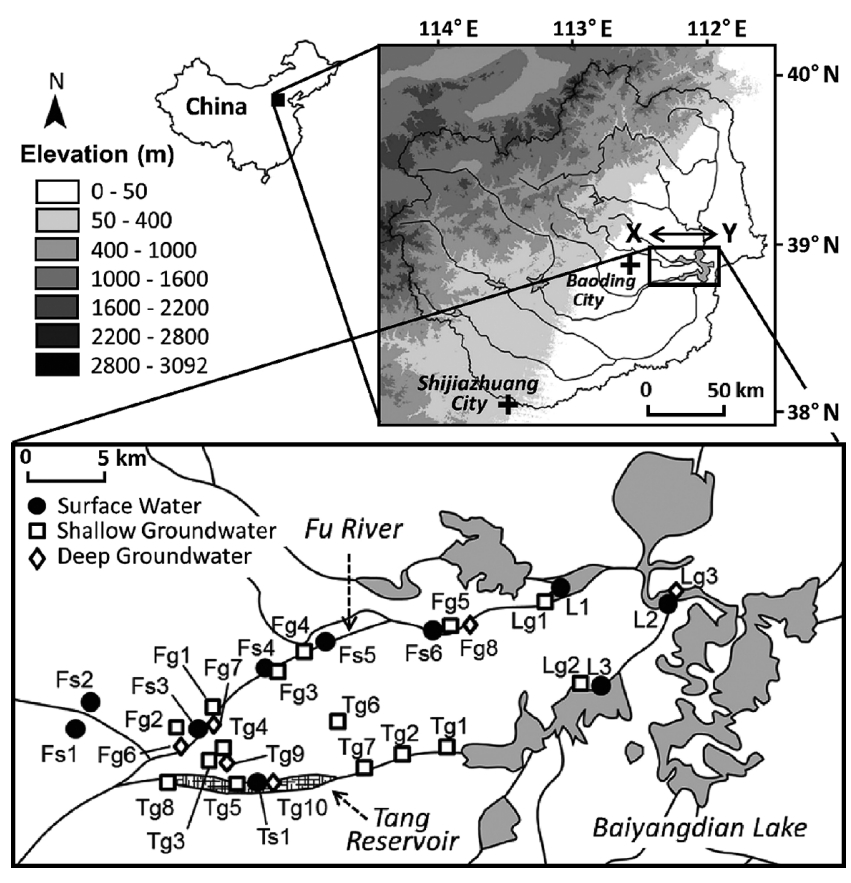

Figure 1. Study area and sampling locations

itation is $580 \mathrm{~mm}$ (Moiwo et al., 2010). Eighty percent of the total rainfall occurs during the flood season (June to August) (Zhuang et al., 2011). The Baiyangdian Lake watershed is a typical alluvial fan; upstream, it is a part of the Taihang Mountain range, whereas the mid and downstream areas are part of the North China Plain. The plain's elevation is less than $50 \mathrm{~m}$. Several rivers discharge into the Baiyangdian Lake. However, extensive dam construction upstream led to decreased river discharge. Most rivers are seasonal and only the Fu River is a perennial stream accepting industrial wastewater and sewage from Baoding City (Qiu et al., 2009; Zhuang et al., 2011). In the 1970s, the Tang River was completely dried up, and a large reservoir was constructed to collect industrial wastewater.

The plain area (Figure 2) comprises Quaternary unconsolidated sediments, silt, clay, and silty clay (Wang et al., 2008). The aquifers are divided into four groups according to the geological substratum, consisting of Neogene-Quaternary sedimentary rocks (Chen et al., 2005).

The present study focuses on the area around the Baiyangdian Lake, Fu River, and Tang Reservoir, a downstream section of the Baiyangdian Lake watershed (Figure 1). Groundwater electrical conductivity (EC) and stable isotopic composition show clearly different values above and below the depth of $150 \mathrm{~m}$ (Supplement Table SI); therefore, this is selected as the limit between shallow and deep groundwater in the present study.

\section{METHODS}

\section{Field measurements and chemical analyses}

Field surveys at 10 sites for surface water (river, lake, and reservoir) and 21 sites for groundwater (shallow and deep aquifers) were performed on June 10-12, 2011 (Figure 1). $\mathrm{EC}, \mathrm{pH}$, and oxidation-reduction potential (ORP) were mea-

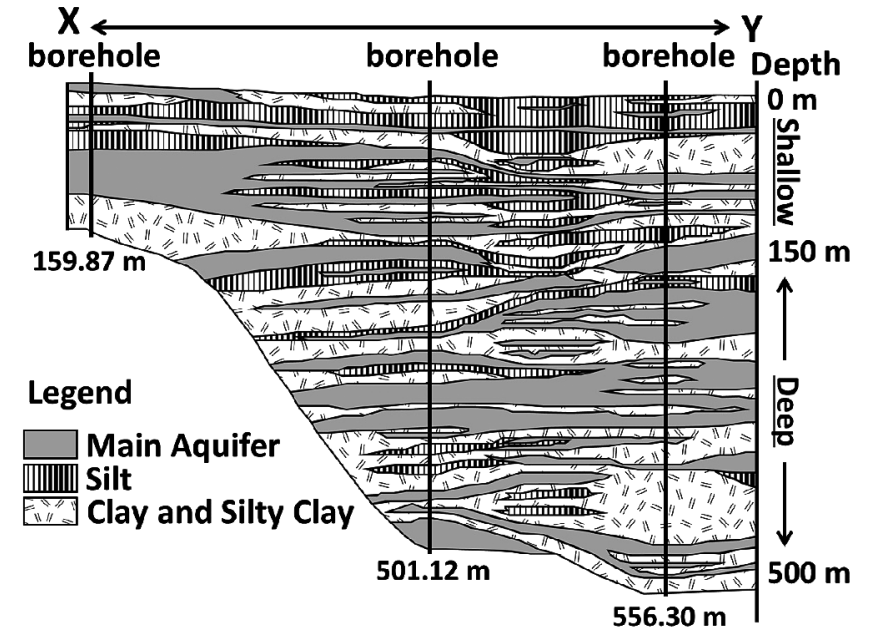

Figure 2. Geological setting along the cross-section $\mathrm{X}-\mathrm{Y}$ in Figure 1 (Groundwater was divided into shallow and deep at the 150 -m threshold)

sured using portable electronic equipment. Well depth information was derived from interviews with the owner of the well and his/her neighbors. The reliability of well depth information is adequately high because sampling wells were selected only when consistent well depth information was obtained through interview with at least 2 local residents including the well owner.

Dissolved inorganic contents and oxygen/hydrogen stable isotopic compositions were analyzed for all water samples. $\mathrm{Cl}^{-}, \mathrm{NO}_{3}^{-}$, and $\mathrm{SO}_{4}{ }^{2-}$ concentrations were analyzed using ion chromatography (SHIMADZU, HIC-10A super) after filtering through a $0.20-\mu \mathrm{m}$ cellulose ester filter. $\mathrm{Na}^{+}, \mathrm{K}^{+}, \mathrm{Ca}^{2+}$ and $\mathrm{Mg}^{2+}$ concentrations were analyzed with an ICP optical emission spectrometer (PERKIN ELMER, Optima 7300DV) after filtering. $\mathrm{HCO}_{3}{ }^{-}$concentration was determined by titration with $0.005 \mathrm{M}$ sulfuric acid. Hydrogen and oxygen stable isotopic compositions were measured with a mass spectrometer (Thermo Fisher, MAT 252). The measured stable isotopic compositions were expressed in the conventional $\delta$-notations represented as per mil deviations from V-SMOW (Vienna Standard Mean Ocean Water).

\section{Principal component analysis and cluster analysis}

Principal component analysis (PCA) and cluster analysis were performed on the geochemical dataset (Supplement Table SI) to detect relationships between the measured variables and group water samples with similar water quality affected by certain factors (human oriented influence, geological effect, and so on). All geochemical data were standardized before the analysis in order to prevent misinterpretation due to wide-range differences in the original data (Panda et al., 2006). PCA allowed the examination of not only water quality characteristics but also water communication among aquifers by overall index or synthesis index (Farnham et al., 2003; McGuire et al., 2005; Chen et al., 2007; Mondal et al., 2010). Principle component loadings (PCLs) were computed to convert the measured values into principal component scores (PCSs). Subsequently, cluster analysis was applied to the PCSs to classify the samples into several groups with similar characteristics. PCSs were clus- 
tered instead of the measured variables to exclude unnecessary and mutually dependent variables (McGuire et al., 2005; Yidana et al., 2011).

\section{RESULTS AND DISCUSSION}

\section{Spatial characteristics of solute concentration and sta- ble isotopes}

Figure 3 shows the spatial distribution of hexa-diagrams of surface water and groundwater in the study area. The most sampled waters are characterized by the $\mathrm{Na}-\mathrm{HCO}_{3}$ type. However, surface water in the Tang Reservoir represents a distinct $\mathrm{Na}-\mathrm{SO}_{4}$ type, and some shallow groundwater around the area shows the same type, though the concentrations of sodium and sulfate ions are lower than the water of the Tang Reservoir. Deep groundwater tends to have a lower concentration of dissolved ions compared with surface water and shallow groundwater. Total ion concentration in shallow groundwater is higher than that in surface water, except for sodium and sulfate ions, which seem to be influenced by the Tang Reservoir, suggesting that shallow groundwater can be influenced by ion dissolution from geology.

Figure 4 shows the relationship between $\delta^{2} \mathrm{H}$ and $\delta^{18} \mathrm{O}$ in the collected water and the annual weighted mean precipitation from 1985 to 2003 (the data was obtained from the Shijiazhuang station of the International Atomic Energy Agency network for China). The local meteoric water line (LMWL) was determined as $\delta^{2} \mathrm{H}=8.2 \delta^{18} \mathrm{O}+9.4$ based on the obtained precipitation data. Surface waters plotted close to the LMWL have originated from precipitation. However, most samples except deep groundwater samples were plotted below the LMWL, indicating a local hydrometeological effect on precipitation. The stable isotopic compositions of deep groundwater ranged from $-74.8 \%$ o $(\mathrm{Fg} 7)$ to $-84.1 \%$ o ( Tg10) for $\delta^{2} \mathrm{H}$ and from $-10.26 \%$ (Fg7) to $-11.09 \%$ ( $\left.\mathrm{Tg} 10\right)$ for $\delta^{18} \mathrm{O}$, which are much depleted and completely different from others. The $\delta$ values of deep groundwater are almost the same as those reported by Chen et al. (2005), suggesting that the residence time of deep groundwater may also be 10,000 to 25,000 years estimated by Chen et al. (2005).

Two surface water samples and one groundwater sample were enriched in both $\delta^{2} \mathrm{H}$ and $\delta^{18} \mathrm{O}$ (L2: $-40.1 \%$ and $-4.14 \%$, L3: $-38.2 \%$ and $-3.57 \%$, Tg1: $-40.9 \%$ and

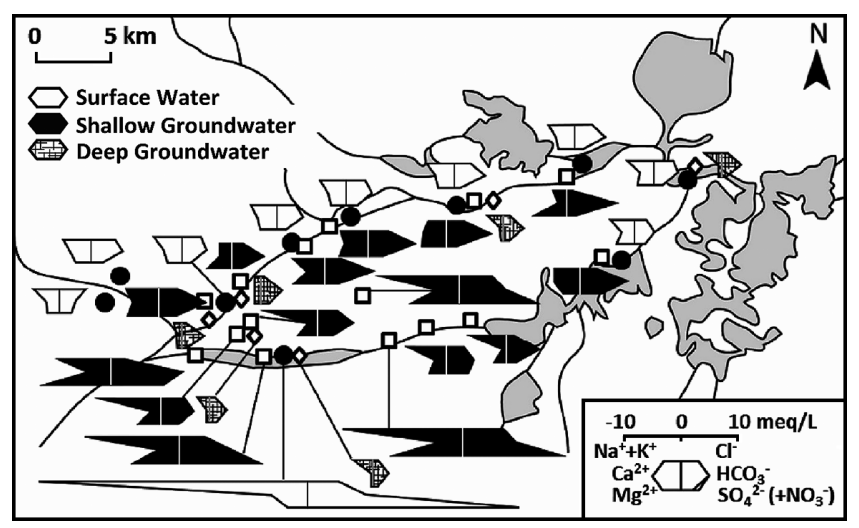

Figure 3. Distribution of hexa-diagrams

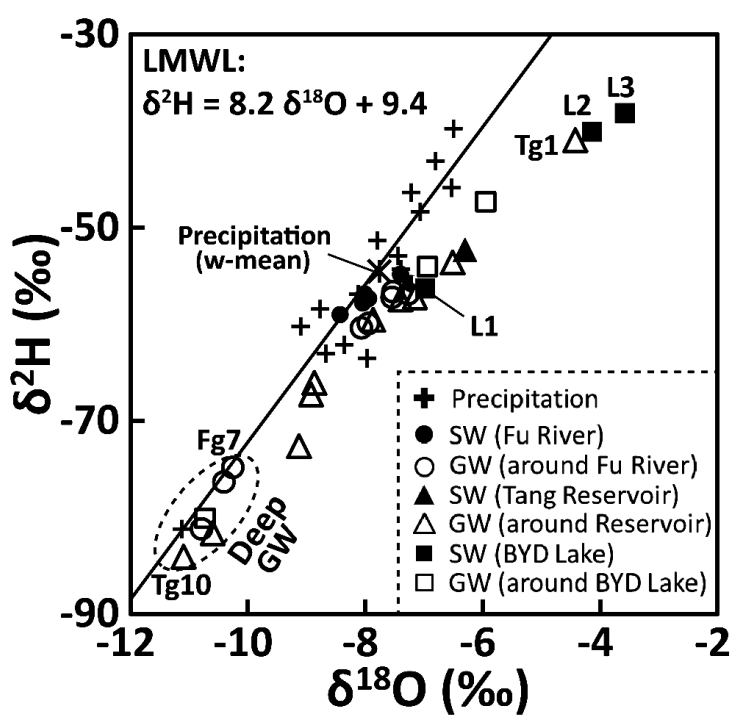

Figure 4. Relationship between stable isotopic compositions of oxygen and hydrogen in surface water (SW) and groundwater (GW) (Precipitation data at Shijiazhuang city were obtained from IAEA WISER database, accessed on October $22,2015)$

$-4.42 \%$ ), whereas the stable isotopic compositions deviated from the LMWL in a direction indicating kinetic fractionation caused by strong evaporation. Limited precipitation during dry seasons increased evaporation and the water isotopic ratio at the Baiyangdian Lake. The stable isotopic compositions of L1 $\left(\delta^{2} \mathrm{H}:-56.3 \%\right.$ o, $\delta^{18} \mathrm{O}:-6.98 \%$ ) are lower than those of L2 and L3. Considering the sampling locations and the water quality (Figure 3), the surface water around L1 includes discharged water from a perennial stream, which inhibits evaporation, in contrast to L2 and L3. In addition, the shallow groundwater stable isotopic compositions vary greatly. Shallow groundwater with higher $\delta$ values could be affected by evaporation, and shallow groundwater plotted close to the LMWL has been influenced by precipitation. Thus, shallow groundwater in the study area originates from multiple recharge sources including surface water, directly recharged precipitation, and upstream groundwater.

\section{Water quality characteristics}

PCA was performed to determine the chemical characteristics and water sources. Table I presents the variable PCLs, eigenvalue and contribution rate of each principal component (PC). The factor selection was based on the values greater than the default eigenvalue criterion of 1 (McGuire et al., 2005). Eigenvalues of first, second, and third PCs are greater than 1 and the cumulative contribution ratio (CCR) until the third PC is $88.5 \%$ (Table I), indicating that these three PCs are enough to consolidate most characteristics of the water samples.

For the first PC, all factors, except nitrate, are positive and mostly have a high PCL. Considering that nitrate and potassium ions exhibit very low concentrations in this area (Supplement Table SI), the first PC probably represents the overall water quality. Particularly, the first PCLs of sodium and sulfate are very high (0.87 and 0.91 , respectively), hence the higher PCS the samples have, the more they are affected 
Table I. Variable principal component loadings (PCLs), eigenvalue, contribution rate, and accumulated contribution rate of each principal component (PC)

\begin{tabular}{llrrr}
\hline Variable & & 1st PC & 2nd PC & 3nd PC \\
\hline $\mathrm{Na}^{+}$ & PCL & 0.87 & -0.01 & -0.47 \\
$\mathrm{~K}^{+}$ & PCL & 0.14 & 0.91 & -0.09 \\
$\mathrm{Ca}^{2+}$ & PCL & 0.82 & 0.27 & 0.18 \\
$\mathrm{Mg}^{2+}$ & PCL & 0.69 & -0.40 & 0.52 \\
$\mathrm{Cl}^{-}$ & PCL & 0.72 & 0.42 & 0.23 \\
$\mathrm{SO}_{4}{ }^{2-}$ & PCL & 0.91 & -0.05 & -0.39 \\
$\mathrm{HCO}_{3}^{-}$ & PCL & 0.76 & -0.32 & 0.41 \\
$\mathrm{NO}_{3}^{-}$ & PCL & -0.13 & 0.87 & 0.29 \\
EC & PCL & 0.98 & 0.03 & -0.18 \\
\hline Eigenvalue & & 4.8 & 2.1 & 1.0 \\
Contribution Rate (\%) & 53.7 & 23.4 & 11.3 \\
Accumulated Contribution Rate (\%) & 53.7 & 77.1 & 88.5 \\
\hline
\end{tabular}

EC, electric conductivity

by the Tang Reservoir, because the reservoir water is characterized by high sodium and sulfate ions (Figure 3 ). In the second PC, nitrate shows a positive high PCL (0.87), and magnesium and bicarbonate show negative PCL values of -0.40 and -0.32 , respectively (Table I). Nitrate accumulation is attributed to chemical fertilizer and sewage in the North China Plain (Hu et al., 2005; Ju et al., 2006), whereas magnesium and bicarbonate originate naturally. Therefore, for the second PC, positive factors correspond to surface loading caused by fertilizers or drainage, whereas negative factors reflect ion dissolution processes from geology.

Next, cluster analysis (Ward method) was applied to the first, second, and third PCSs of each sample to group water samples with similar characteristics (Figure 5). According to the dendrogram (Supplement Figure S1), some shallow groundwater samples around the Fu River and Tang Reservoir

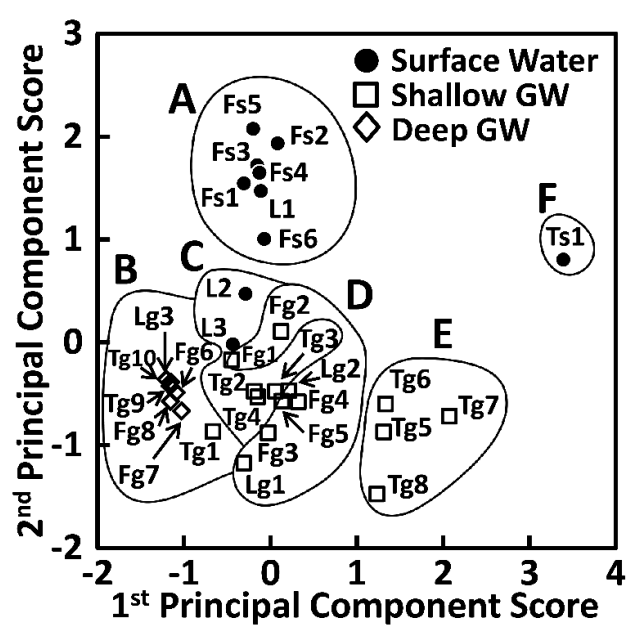

Figure 5. Distribution of first and second PCSs of the PCA, and the result of cluster analysis using PCSs 1, 2, and 3 are divided into the same group on the four-group-separation in spite of much different water quality (Figure 3 ). On the other hand, a shallow groundwater sample (Tg8) with not distinct water quality (Figure 3 ) is isolated on the sevengroup-separation. Therefore, five/six-group-separations are reasonable. In this study, the six-group-separation was applied.

Groups C and D have a very complex border due to the third PCS. Further PC interpretation including third PC is needed for distinguishing groups $\mathrm{C}$ and $\mathrm{D}$. Group $\mathrm{A}$ is the $\mathrm{Fu}$ River surface water. Group B includes all deep groundwater samples and one shallow groundwater sample taken near the Baiyangdian Lake. Group C includes the Baiyangdian Lake surface water and some shallow groundwater samples around the Tang Reservoir. Group D includes the shallow groundwater around the $\mathrm{Fu}$ River and Baiyangdian Lake. Group E is shallow groundwater obtained near the Tang Reservoir and Group F is the surface water of the Tang Reservoir.

Considering the axis interpretation, Groups A, C, and D have general water quality in the study field. Groups A and F with positive second PCSs are affected by anthropogenic factors, whereas other groups might be influenced by natural factors. Additionally, Group E shifts toward Group F, away from Groups A, C, and D, perhaps due to an interaction between the Tang Reservoir and surrounding groundwater.

Interaction between surface water and shallow groundwater

Figure 6 shows the distribution of hexa-diagrams and $\delta^{18} \mathrm{O}$ and $\mathrm{NO}_{3}^{-}$concentrations of water samples along sections A-B and X-Y. Shallow groundwater around the Baiyangdian Lake (e.g., Tg1, Lg1, and Lg2) is dominantly recharged by the lake, because of similar $\delta^{18} \mathrm{O}$ to that of Lake waters (L1 for Lg1, L3 for $\operatorname{Tg} 1$ and $\operatorname{Lg} 2$ ) and close first PCS corresponding to the general water quality index (Figure 5). However, Tg2, even though it is located near the lake, shows a lower $\delta^{18} \mathrm{O}$ compared with that of L3, suggesting no clear recharge effect by the Baiyangdian Lake.

According to the hexa-diagram pattern and the $\delta^{18} \mathrm{O}$ of water, we suggest that the shallow groundwater near the Tang Reservoir (Tg5, Tg6, Tg7, and Tg8) is recharged by the reservoir; the $\mathrm{Na}_{-} \mathrm{SO}_{4}$ similarity between these waters reflects the process, though a little higher $\mathrm{Mg}^{2+}$ concentration might be geologically oriented due to the negative first

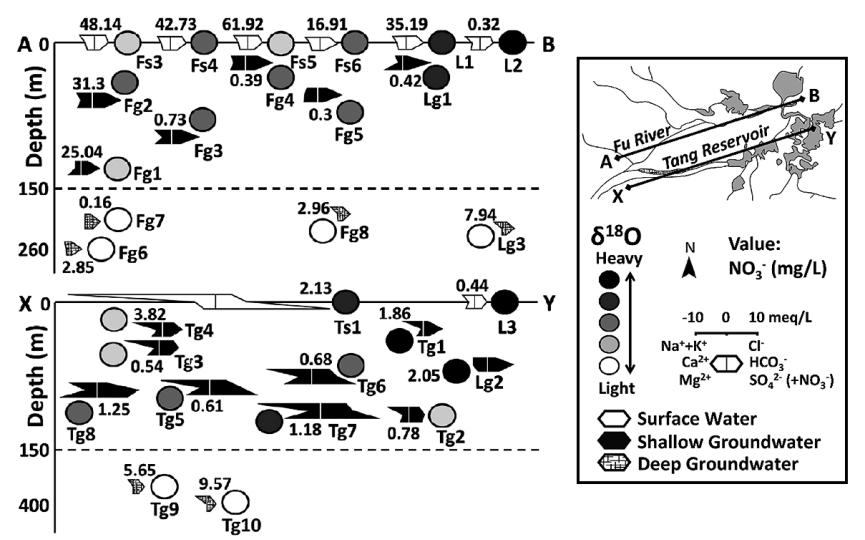

Figure 6. Distribution of $\delta^{18} \mathrm{O}$ and water quality along crosssections A-B and X-Y 
PCS (Figure 5). On the other hand, $\mathrm{Tg} 2, \mathrm{Tg} 3$, and $\mathrm{Tg} 4$, which are placed in the same group as the Baiyangdian Lake surface water, show different chemical characteristics and stable isotopic compositions from other shallow groundwater around the Tang Reservoir; hence, they do not reveal the interaction with the Tang Reservoir water.

$\mathrm{Fu}$ River surface water with positive second PCS is affected by anthropogenic impact such as nitrogen load by fertilizer and drainage. Shallow groundwater around the Fu River has negative second PCS, which seems mostly affected by the geological processes, and is clustered into a completely different group (Figure 5). However, in terms of comprehensive water quality and isotopic signal, both waters exhibit similar values. In addition, some shallow groundwater samples from around the $\mathrm{Fu}$ River show a $\mathrm{NO}_{3}^{-}$concentration similar to that of the river, though deep groundwater has a much lower $\mathrm{NO}_{3}^{-}$concentration than surface water. The surface waters in the Tang Reservoir and Baiyangdian Lake have lower $\mathrm{NO}_{3}{ }^{-}$concentrations than the $\mathrm{Fu}$ River. The lake and reservoir are stagnant due to the lack of inflow discharge during the dry season, causing denitrification, whereas the $\mathrm{Fu}$ River is in an aerobic state with perennial discharge. In addition, abundant pollutants in the Tang Reservoir may induce a reductive process, as shown by the ORP value (-189). Most groundwater has positive ORP, suggesting a less stagnant state in groundwater in this region. Therefore, shallow groundwater with $\delta^{18} \mathrm{O}$ and $\mathrm{NO}_{3}{ }^{-}$concentrations similar to those of surface water is directly recharged by the Fu River, whereas shallow groundwater with a relatively low $\mathrm{NO}_{3}^{-}$concentration might be affected by not only the Fu River but also differently-originated groundwater through the mixing process.

\section{Interaction between shallow and deep groundwater}

Deep groundwater samples are placed into the same group, and the water quality differs slightly from the other samples (Figure 5). Hence, deep groundwater is apparently isolated. However, relatively-high $\mathrm{NO}_{3}{ }^{-}$concentrations were observed in some samples taken from wells deeper than $200 \mathrm{~m}$ (Figure 6). Shindo et al. (2004) mentioned that fertilizer and livestock waste are the major sources of high $\mathrm{NO}_{3}{ }^{-}$ concentration in the groundwater in agricultural areas of monsoon Asia. In addition, domestic sewage and leakage from the sewage pipes cause a high nitrate load in urban areas (Umezawa et al., 2008; Kaushal et al., 2011). Liu et al. (2005) observed considerably-high nitrate concentrations in groundwater deeper than $300 \mathrm{~m}$. Possibly, this is caused by the intrusion of shallow groundwater with high $\mathrm{NO}_{3}^{-}$concentration into deep aquifers without any denitrification or dilution, which might result from excessive pumping of deep groundwater leading to a hydraulic gradient between the shallow and deep aquifers across the aquitard (Onodera et al., 2009).

Liu et al. (2005) also reported high $\mathrm{NO}_{3}^{-}$concentrations in the deep aquifer and attributed them to measurement errors or interaction between the shallow and deep aquifers. In the present research, groundwater stable isotopic signals occasionally show similar values in the shallow and deep aquifers (e.g., Fg1 and Fg7, Tg2 and Tg10). Considering both stable isotopic compositions and nitrate concentrations, this is likely to be caused by partial communication between the shallow and deep aquifers in the Baiyangdian Lake watershed.

\section{CONCLUSIONS}

In the present study, multiple tracers were analyzed and classification approaches were attempted, in order to clarify the surface water and groundwater continuum flow system downstream of the Baiyangdian Lake watershed, North China Plain. All samples, obtained from surface water, shallow groundwater, and deep groundwater, were analyzed for main dissolved inorganic ion concentrations as well as oxygen and hydrogen stable isotopic compositions.

The Fu River, Tang Reservoir, and Baiyangdian Lake waters exhibit different stable isotopic and geochemical characteristics. The water quality in the Tang Reservoir is characterized by a distinct $\mathrm{Na}-\mathrm{SO}_{4}$ type derived from industrial wastewater. The Baiyangdian Lake shows enriched stable isotopic signals because of evaporation. The anthropogenic impact is significant on the Fu River water, as indicated by its high nitrate ion concentration.

Some shallow groundwater samples taken around the Tang Reservoir include the same $\mathrm{Na}-\mathrm{SO}_{4}$ type as the surface water. In addition, part of the shallow groundwater near the Baiyangdian Lake has enriched stable isotopic compositions. Shallow groundwater around the Fu River shows similar stable isotopic compositions to surface water, whereas dominant shallow groundwater does not exhibit a nitrate concentration as high as that of surface water, with some exceptions. Not all shallow groundwater samples show chemical and stable isotopic values similar to those of surface water, indicating that surface water does not affect all shallow groundwater, but recharges shallow groundwater at specific regions in the groundwater flow system.

Most deep groundwater samples show different chemical and isotopic signals from surface water and shallow groundwater. However, a slightly-high nitrate-ion concentration is observed in some parts of deep aquifers. In addition, some shallow groundwater samples have similar isotopic signals with deep groundwater. Both nitrate-ion concentration and stable isotopic signals suggest partial communication between shallow and deep aquifers.

\section{ACKNOWLEDGEMENTS}

The authors would like to thank Dr. Ruiqiang Yuan (Shanxi University, China) and Dr. Shiqin Wang (Chinese Academy of Sciences, China) for their support in the field survey. The authors thank Dr. Yutaka Abe (Suntory Global Innovation Center, Japan) for useful discussion and technical advices to improve this research. This work was supported by JSPS KAKENHI Grants Number 23401002 and 23241016.

\section{SUPPLEMENTS}

Figure S1. Dendrogram of the cluster analysis using the Ward method

Table SI. Hydrochemical and stable isotopic characteristics of collected water samples 


\section{REFERENCES}

Barthel R. 2014. HESS opinions "Integration of groundwater and surface water research: an interdisciplinary problem?" Hydrology and Earth System Sciences 18: 2615-2628. DOI: 10.5194/hess-18-2615-2014.

Chen KP, Jiao JJ, Huang JM, Huang RQ. 2007. Multivariate statistical evaluation of trace elements in groundwater in a coastal area in Shenzhen, China. Environmental Pollution 147: 771780. DOI: 10.1016/j.envpol.2006.09.002.

Chen ZY, Nie ZL, Zhang ZJ, Qi JX, Nan YJ. 2005. Isotopes and sustainability of ground water resources, North China Plain. Ground Water 43: 485-493.

Cui BS, Li X, Zhang KJ. 2010. Classification of hydrological conditions to assess water allocation schemes for Lake Baiyangdian in North China. Journal of Hydrology 385: 247256. DOI: $10.1016 /$ j.jhydrol.2010.02.026.

Farnham IM, Johannesson KH, Singh AK, Hodge VF, Stetzenbach KJ. 2003. Factor analytical approaches for evaluating groundwater trace element chemistry data. Analytica Chimica Acta 490: 123-138. DOI: 10.1016/S0003-2670(03)00350-7.

Gmati S, Tase N, Tsujimura M, Tosaki Y. 2011. Aquifers interaction in the southwestern foot of Mt. Fuji, Japan, examined through hydrochemistry and statistical analyses. Hydrological Research Letters 5: 58-63. DOI: 10.3178/hrl.5.58.

Hu K, Huang Y, Li H, Li B, Chen D, White RE. 2005. Spatial variability of shallow groundwater level, electrical conductivity and nitrate concentration, and risk assessment of nitrate contamination in North China Plain. Environment International 31: 896-903. DOI: 10.1016/j.envint.2005.05.028.

Jolly ID, McEwan KL, Holland KL. 2008. A review of groundwatersurface water interactions in arid/semi-arid wetlands and the consequences of salinity for wetland ecology. Ecohydrology 1: 43-58. DOI: 10.1002/eco.6.

Ju XT, Kou CL, Zhang FS, Christie P. 2006. Nitrogen balance and groundwater nitrate contamination: Comparison among three intensive cropping systems on the North China Plain. Environmental Pollution 143: 117-125. DOI: 10.1016/j. envpol.2005.11.005.

Kaushal SS, Groffman PM, Band LE, Elliott EM, Shields CA, Kendall C. 2011. Tracking nonpoint source nitrogen pollution in human-impacted watersheds. Environmental Science and Technology 45: 8225-8232. DOI: 10.1021/es200779e.

Keery J, Binley A, Crook N, Smith J. 2007. Temporal and spatial variability of groundwater-surface water fluxes: Development and application of an analytical method using temperature time series. Journal of Hydrology 336: 1-16. DOI: 10.1016/j. jhydrol.2006.12.003.

Li FD, Pan GY, Tang CY, Zhang QY, Yu JJ. 2008. Recharge source and hydrogeochemical evolution of shallow groundwater in a complex alluvial fan system, southwest of North China Plain. Environmental Geology 55: 1109-1122. DOI: 10.1007/ s00254-007-1059-1.

Liu CL, Xie GD, Huang HQ. 2006. Shrinking and drying up of Baiyangdian Lake wetland: A natural or human cause? Chinese Geographical Science 16: 314-319. DOI: 10.1007/ s11769-006-0314-9.

Liu GD, Wu WL, Zhang J. 2005. Regional differentiation of nonpoint source pollution of agriculture-derived nitrate nitrogen in groundwater in northern China. Agriculture, Ecosystems and Environment 107: 211-220. DOI: 10.1016/j.agee.2004.
11.010

Liu J, Zheng CM, Zheng L, Lei YP. 2008. Ground water sustainability: Methodology and application to the North China Plain. Ground Water 46: 897-909. DOI: 10.1111/j.1745-6584. 2008.00486.x.

Liu YP, Yamanaka T. 2012. Tracing groundwater recharge sources in a mountain-plain transitional area using stable isotopes and hydrochemistry. Journal of Hydrology 464-465: 116-126. DOI: 10.1016/j.jhydrol.2012.06.053.

McGuire JT, Long DT, Hyndman DW. 2005. Analysis of recharge-induced geochemical change in a contaminated aquifer. Ground Water 43: 518-530. DOI: 10.1111/j.1745-6584. 2005.0040.x.

Moiwo JP, Yang YH, Li HL, Han SM, Yang YM. 2010. Impact of water resource exploitation on the hydrology and water storage in Baiyangdian Lake. Hydrological Processes 24: 3026 3039. DOI: 10.1002/hyp.7716.

Mondal NC, Singh VP, Singh VS, Saxena VK. 2010. Determining the interaction between groundwater and saline water through groundwater major ions chemistry. Journal of Hydrology 388: 100-111. DOI: 10.1016/j.jhydrol.2010.04.032.

Nakaya S, Uesugi K, Motodate Y, Ohmiya I, Komiya H, Masuda H, Kusakabe M. 2007. Spatial separation of groundwater flow paths from a multi-flow system by a simple mixing model using stable isotopes of oxygen and hydrogen as natural tracers. Water Resources Research 43: W09404. DOI: 10.1029/ 2006WR005059.

Onodera S, Saito M, Sawano M, Hosono T, Taniguchi M, Shimada J, Umezawa Y, Lubis RF, Buapeng S, Delinom R. 2009. Erratum to "Effects of intensive urbanization on the intrusion of shallow groundwater into deep groundwater: Examples from Bangkok and Jakarta". Science of the Total Environment 407: 3209-3217. DOI: 10.1016/j.scitotenv.2009.01.049.

Panda UC, Sundaray SK, Rath P, Nayak BB, Bhatta D. 2006. Application of factor and cluster analysis for characterization of river and estuarine water systems - A case study: Mahanadi River (India). Journal of Hydrology 331: 434-445. DOI: 10. 1016/j.jhydrol.2006.05.029.

Qin DJ, Qian YP, Han LF, Wang ZM, Li C, Zhao ZF. 2011. Assessing impact of irrigation water on groundwater recharge and quality in arid environment using CFCs, tritium and stable isotopes, in the Zhangye Basin, Northwest China. Journal of Hydrology 405: 194-208. DOI: 10.1016/j.jhydrol.2011.05. 023.

Qiu RZ, Li YX, Yang ZF, Shi JH. 2009. Influence of water quality change in Fu River on Wetland Baiyangdian. Frontiers of Earth Science in China 3: 397-401. DOI: 10.1007/s11707009-0056-y.

Scanlon BR, Keese KE, Flint AL, Flint LE, Gaye CB, Edmunds WM, Simmers I. 2006. Global synthesis of groundwater recharge in semiarid and arid regions. Hydrological Processes 20: 3335-3370. DOI: 10.1002/hyp.6335.

Shindo J, Okamoto K, Guo YL, Toda H, Kawanishi T, Tanaka T, Kawashima H. 2004. Evaluation of environmental impact and nitrogen loading in East Asia using watershed-based nitrogen circulation model. Journal of Earth Environment 9: 93-99 (in Japanese).

Shivanna K, Kulkarni UP, Joseph TB, Navada SV. 2004. Contribution of storms to groundwater recharge in the semiarid region of Karnataka, India. Hydrological Processes 18: 473-485. DOI: 10.1002/hyp.1323.

Shu YQ, Villholth KG, Jensen KH, Stisen S, Lei YP. 2012. 
Integrated hydrological modeling of the North China Plain: Options for sustainable groundwater use in the alluvial plain of Mt. Taihang. Journal of Hydrology 464-465: 79-93. DOI: 10.1016/j.jhydrol.2012.06.048.

Sophocleous M. 2002. Interactions between groundwater and surface water: the state of the science. Hydrogeology Journal 10: 52-67. DOI: 10.1007/s10040-001-0170-8.

Tsujimura M, Abe Y, Tanaka T, Shimada J, Higuchi S, Yamanaka T, Davaa G, Oyunbaatar D. 2007. Stable isotopic and geochemical characteristics of groundwater in Kherlen River basin, a semi-arid region in eastern Mongolia. Journal of Hydrology 333: 47-57. DOI: 10.1016/j.jhydrol.2006.07.026.

Umezawa Y, Hosono T, Onodera S, Siringan F, Buapeng S, Delinom R, Yoshimizu C, Tayasu I, Nagata T, Taniguchi M. 2008. Sources of nitrate and ammonium contamination in groundwater under developing Asian megacities. Science of the Total Environment 404: 361-376. DOI: 10.1016/j.scitotenv.2008. 04.021.

Wang SQ, Shao JL, Song XF, Zhang YB, Huo ZB, Zhou XY. 2008. Application of MODFLOW and geographic information system to groundwater flow simulation in North China Plain, China. Environmental Geology 55: 1449-1462. DOI: 10.1007/s00254-007-1095-x.

Winter TC, Harvey JW, Franke OL, Alley WM. 1998. Ground water and surface water: A single resource. U.S. Geological Survey Circular 1139, USA; 79.

Yangui H, Zouari K, Trabelsi R, Rozanski K. 2011. Recharge mode and mineralization of groundwater in a semi-arid region: Sidi Bouzid plain (central Tunisia). Environmental Earth Sciences 63: 969-979. DOI: 10.1007/s12665-010-0771-4.

Yidana SM, Banoeng-Yakubo B, Akabzaa T, Asiedu D. 2011. Characterization of the groundwater flow regime and hydrochemistry of groundwater from the Buem formation, Eastern Ghana. Hydrological Processes 25: 2288-2301. DOI: 10. 1002/hyp.7992.

Yuan RQ, Song XF, Han DM, Zhang L, Wang S. 2013. Upward recharge through groundwater depression cone in piedmont plain of North China Plain. Journal of Hydrology 500: 1-11. DOI: 10.1016/j.jhydrol.2013.06.056.

Zhuang CW, Ouyang ZY, Xu WH, Bai Y, Zhou WQ, Zheng H, Wang XK. 2011. Impacts of human activities on the hydrology of Baiyangdian Lake, China. Environmental Earth Sciences 62: 1343-1350. DOI: 10.1007/s12665-010-0620-5. 